\title{
EVOLUÇÃO DO RELEVO NA SERRA DO MAR NO ESTADO DE SÃO PAULO A PARTIR DE UMA CAPTURA FLUVIAL ${ }^{1}$
}

\author{
Déborah de Oliveira* \\ J osé Pereira de Queiroz Neto**
}

\section{RESUMO:}

A Serra do Mar surgiu por recuo erosivo da falha Paleocênica de Santos, situada mais a leste, na plataforma continental sul-americana. A Falha de Santos provocou o abatimento do planalto, correspondente à superfície Japi. Com o recuo erosivo das escarpas da Serra do Mar, rios do planalto foram capturados, como o rio Guaratuba, em Boracéia-SP. A bacia do alto rio Guaratuba localiza-se no Parque Estadual da Serra do Mar, no reverso imediato da escarpa da Serra do Mar, a

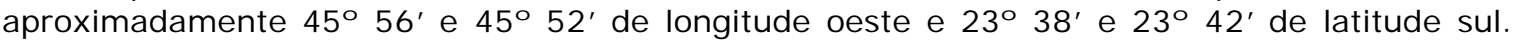

O rio Guaratuba corre de NE para SW, em seu primeiro trecho. A mudança brusca de direção do rio para N-S sugeriu tratar-se de uma captura fluvial por recuo das cabeceiras, como conseqüência da erosão regressiva da Serra do Mar. Algumas evidências dessa captura foram encontradas: a referida mudança brusca de direção do rio, que passa de NE-SW para N-S, cortando os alinhamentos NESW das rochas, no cotovelo de captura, próximo à escarpa; um vale abandonado pantanoso próximo ao cotovelo de captura, correspondendo a um terraço com seixos do antigo leito do rio Guaratuba, anterior à captura; o perfil longitudinal do rio Guaratuba com uma forte ruptura de declive no cotovelo de captura.

\section{PALAVRAS-CHAVE:}

Serra do Mar; recuo erosivo; captura fluvial; rio Guaratuba.

\section{ABSTRACT:}

Serra do Mar emerged by erosional processes of Santos fault line to the Upper Cretaceous, in the present continental south-american platform. Santos fault line caused abatement of the plateau, which corresponds at Japi erosional surface. The scarp's retreat of Serra do Mar caused the river capture of plateau's rivers as Guaratuba, in Boracéia-SP. Alto Guaratuba basin is located at Parque Estadual da Serra do Mar, near Serra do Mar scarp, approximately at 45 56' and 450 52' of longitude west and 23 38' and 23 $42^{\prime}$ of latitude south. Guaratuba river flows from NE-SW on the plateau to N-S on the scarp and its change suggests that Guaratuba is captured by headward erosion, as result of Serra do Mar's regressive erosion. Some evidences are found: the elbow of capture in a sharp change from NE-SW to N-S, cutting rocks' structural lines, near the scarp; a wind gap swampy and gravelly, near the elbow of capture, as an ancient Guaratuba's riverbed; river profile of Guaratuba as a powerful slope rupture.

\section{KEY WORDS:}

Serra do Mar; regressive erosion; river capture; Guaratuba river. 
Introdução: a escarpa da Serra do Mar em São Paulo

A Serra do Mar estende-se do Rio de Janeiro a Santa Catarina, formando um conjunto de escarpas festonadas. Em São Paulo, ela impõe-se como típica borda de planalto, nivelada em altitudes de 800 a $1.200 \mathrm{~m}$. Conforme ROSS (1985), a Serra do Mar pertence à unidade morfoescultural dos Planaltos em Cinturões Orogênicos, no subcompartimento dos Planaltos e Serras do Atlântico Leste-Sudeste. Segundo esse autor, sua gênese vincula-se a vários ciclos de dobramentos acompanhados de metamorfismos regionais, falhamentos e extensas intrusões. Domina no Planalto Atlântico um modelado composto por formas convexas, com vales profundos e elevada densidade de drenagem. Sua origem está relacionada a processos tectônicos de movimentação vertical ocorridos no Cenozóico e que, conforme ALMEIDA \& CARNEIRO (1998), surgiu a partir da falha de Santos situada na plataforma continental, de onde recuou por erosão até a posição atual, atingindo a falha de Cubatão em alguns trechos.

\section{FIGURA 1 - Esboço morfoestutural da Serra do Mar no Estado de São Paulo}

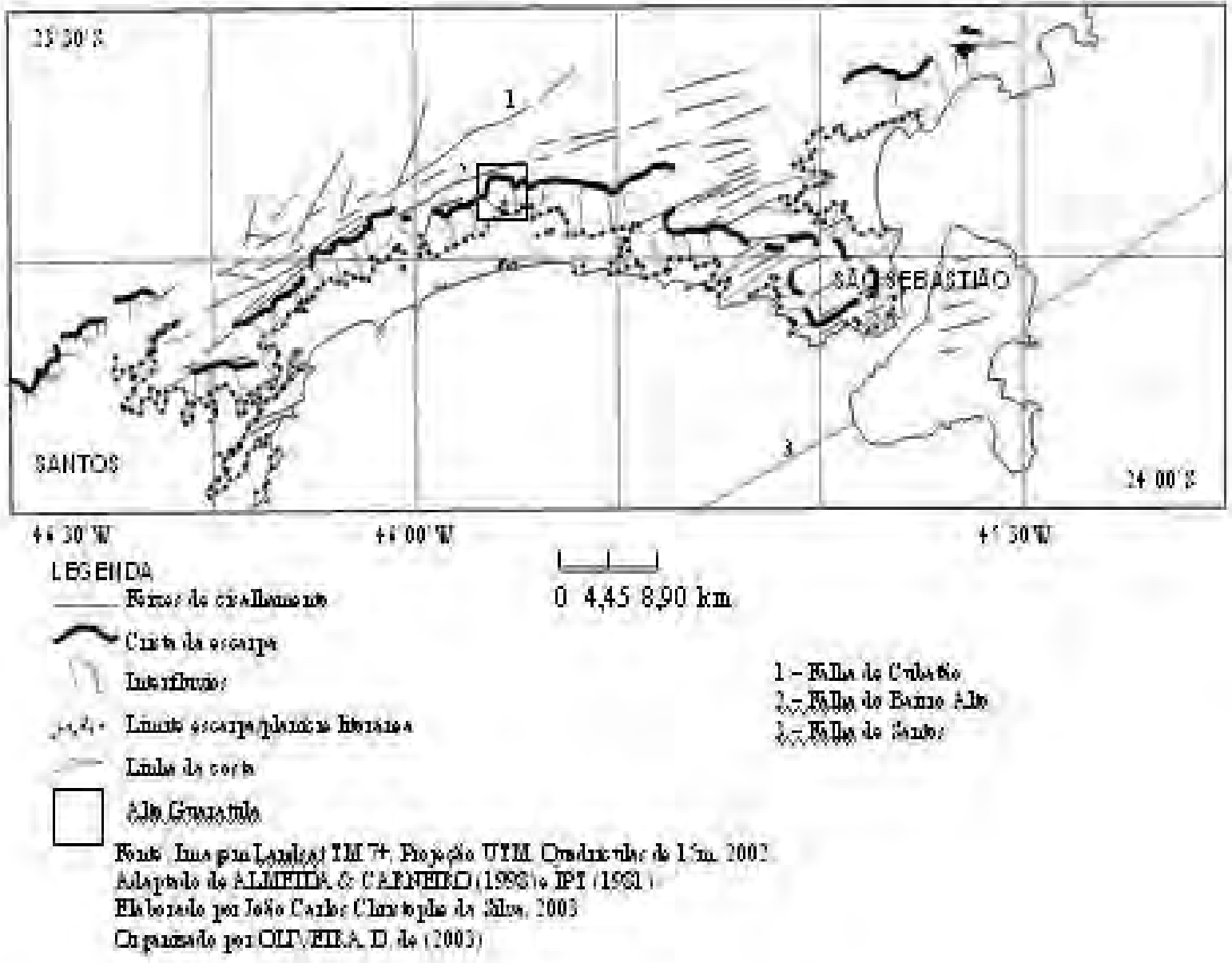


Para ZALÁN \& OLIVEIRA (2005), a Serra do Mar Cretácea constituía um imenso planalto maciço, cujo flanco leste era provavelmente abrupto e tinha um desnível de $3.000 \mathrm{~m}$ para a Bacia de Santos $(2.000 \mathrm{~m}$ acima do nível do mar). Estes autores sugerem que este megaplanalto começou a rachar e colapsar localmente no final do Paleoceno e mais abrangentemente no início do Eoceno. Este abatimento individualizou riftes paralelos à costa, formando longos corredores de grábens, como o Gráben de Santos.

A vertente atlântica do sudeste do Brasil, em especial o trecho que inclui as serras da Mantiqueira, do Mar e o litoral, representa o campo mais complexo no que diz respeito às relações genéticas entre o relevo e os processos geológicos que vêm ocorrendo ao longo do tempo. (ALMEIDA \& CARNEIRO, 1998)

A partir da última orogênese précambriana e ao longo de todo o Paleozóico e boa parte do Mesozóico, período de certa quietude tectônica, as cadeias de montanhas geradas passam a sofrer erosão. Parte-se do pressuposto de que este longo tempo de exposição aos agentes erosivos pode ter destruído todo o registro da superfície da crosta e, sobretudo, pelo fato de que as rochas e estruturas aflorantes formaram-se a partir de fenômenos geodinâmicos que só acontecem a milhares de metros de profundidade. Pode-se concluir que a grande herança pré-cambriana para a formação do atual relevo consiste na qualidade e diversidade de seus tipos litológicos, principalmente em relação às suas características texturais, granulométricas e mineralógicas e na trama estrutural de primeira ordem, representada pelos grandes feixes de direção NE-SW (Cinturão Transpressivo Paraíba do Sul) que, por sua vez, controlam as estruturas de menor grandeza e dimensões, nas quais rochas de diferentes naturezas podem aparecer desde preservadas até pouco ou intensamente milonitizadas.
Além da gênese das rochas basálticas e alcalinas, que completam o quadro litológico da região, este regime tectônico do Paleógeno resulta, por soerguimento das porções ocidentais, e abatimento das orientais, na formação de importantes desníveis topográficos e basculamento de blocos, forçando um reequilíbrio do terreno, seja pela erosão remontante, seja pela deposição de sedimentos. Destaca-se o fato de que este é o marco inicial da morfogênese de todo o Sudeste Atlântico Brasileiro, pois a configuração do relevo, a macro organização da drenagem e a própria situação costeira decorrem deste processo (SILVA, 1999), muito embora a atual Serra do Mar provavelmente não ocupe a mesma posição original, devido ao recuo da escarpa por erosão, e cujo desmonte veio a contribuir para o preenchimento da bacia de Santos e, também, para a formação do Grupo Bauru da bacia do Paraná (ALMEIDA \& CARNEIRO, 1998).

O processo erosivo que no final do Cretáceo Superior, levou ao desenvolvimento da "superfície Japi", exumou o embasamento cristalino, com seus diques de diabásio e intrusões alcalinas na área costeira. A erosão teria sido muito mais intensa na vertente oceânica, de acentuado declive, que na continental. Ali a erosão, por ação dos rios, do mar e de movimentos de massa, fez recuar a escarpa até três a quatro dezenas de quilômetros, abandonando numerosas ilhas e entalhando a "superfície Japi" e mais tarde as superfícies neogênicas nela embutidas. Os detritos dessa erosão foram então levados para a borda da plataforma continental (formações Santos, Juréia e Itajaí-Açu) e para a Bacia do Paraná (formação Bauru). Essa superfície, no entanto, foi deformada por flexuras e grandes falhamentos entre o final do Cretáceo e o início do Terciário, prosseguindo menos intensamente no Eoceno/Oligoceno e provavelmente até o Mesomioceno. (ALMEIDA \& CARNEIRO, 1998) 
Os falhamentos escalonados da Serra da Mantiqueira e da Serra do Mar comandaram a drenagem em declives cada vez mais acentuados. Os níveis de base mais próximos e cada vez mais baixos devido ao tectonismo post-cretáceo no sudeste do Planalto Atlântico teriam forçado uma inversão progressiva de partes das drenagens que iam para o interior através de "múltiplas capturas", como assinalara AB' SÁBER (1954). Com o recuo erosivo das escarpas da Serra do Mar, alguns rios do planalto foram capturados, como o rio Guaratuba, em Boracéia-SP.

A captura fluvial (river capture ou stream piracy) corresponde ao desvio natural das águas de uma bacia fluvial para outra, promovendo a expansão de uma drenagem em detrimento da vizinha. Ela pode ocorrer através da absorção, do recuo das cabeceiras, do aplainamento lateral, do transbordamento ou do desvio subterrâneo CHRISTOFOLETTI (1975). Conforme MILLER (1915), um rio comete pirataria (piracy) ao conquistar seu vizinho.

Pode-se observar um conjunto de evidências que confirmam a ocorrência de capturas fluviais, como o que chamamos de cotovelos de captura (elbows of capture), que correspondem a uma mudança brusca no curso de um rio numa curva de 90 o e que são influenciados por fatores geológicos, aos quais o rio ajusta-se; colos ou vales mortos, secos ou abandonados (cols or wind-gaps), sabendo-se que a existência de um colo não é uma prova de captura, mas a presença de cascalhos no seu vale. O vale seco ou abandonado (wind gap) é apenas um colo no topo do interflúvio cortado pelo recuo da nascente de dois rios, que tem suas nascentes em oposição uma à outra. O perfil longitudinal do rio ajuda a reconstituir sua história, assinalando rupturas de declive quando seu nível de base rebaixa-se no local onde é capturado por outro rio. (SMALL, 1977)

A bacia do alto rio Guaratuba localizase no Parque Estadual da Serra do Mar e atravessa a Estação Biológica de BoracéiaUSP, no reverso imediato da escarpa da Serra do Mar, a aproximadamente $45^{\circ} 56^{\prime}$ e $45^{\circ} 52^{\prime}$ de longitude oeste e $23^{\circ} 38^{\prime}$ e $23^{\circ}$ $42^{\prime}$ de latitude sul, situa-se no município de Bertioga, que limita-se a norte com o município de Salesópolis e a oeste com o município de Biritiba Mirim e mede aproximadamente $40 \mathrm{~km}^{2}$. 


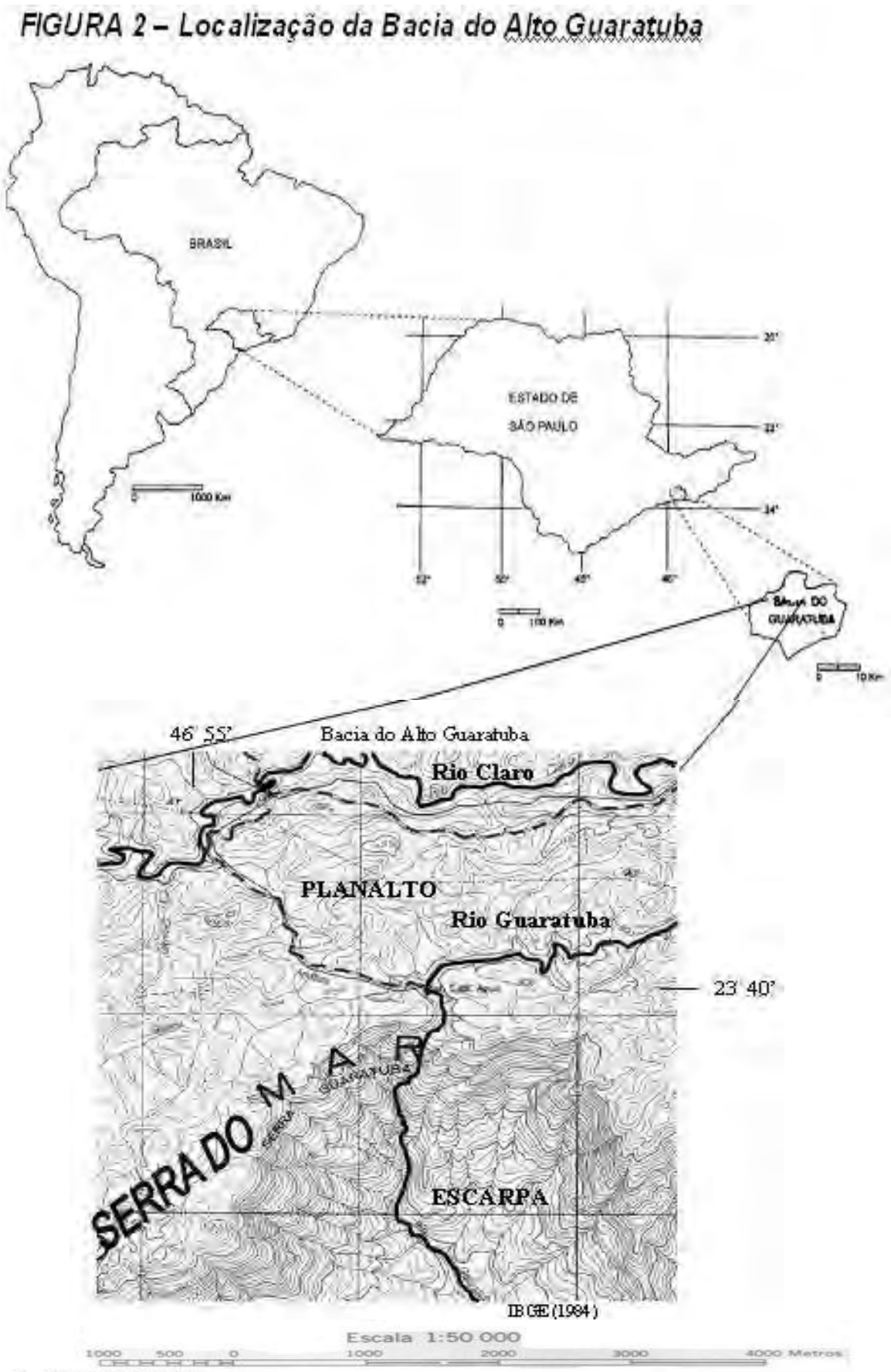


A drenagem que formou-se no planalto, escarpa e planície individualizou ainda mais estes compartimentos. No planalto ela adaptou-se às formas colinosas e amorreadas guiada pelas direções estruturais. Nas escarpas da Serra do Mar, os rios têm suas cabeceiras no alto da serra e, em seguida, vencem esta faixa estreita de cerca de $5 \mathrm{~km}$, constituída por escarpas abruptas, rupturas violentas de declive e alguns rios cortando transversalmente as direções estruturais. (MACHADO, 1979)

ROSSI (1999) divide a área de estudo em dois compartimentos geomorfológicos: Planalto e Escarpa, onde predominam os gnaisses e granitos, respectivamente. Apresenta vegetação típica de floresta Pluvial Tropical, com predomínio de mata alta, com 20 a 25 metros de altura no Planalto e mata de porte alto a médio (15 a $20 \mathrm{~m}$ de altura) na Escarpa. Sofre influência da Massa Tropical Atlântica e possui clima tropical úmido, com temperaturas médias elevadas e chuvas periódicas e abundantes.

O Planalto apresenta dois rios principais: o Claro, que localiza-se mais ao norte e o Guaratuba, localizado mais próximo da Escarpa. Ambos acompanham a direção brasileira NE-SW e a falha do Bairro Alto, localizada no Planalto (rever FIGURA 1 ). A drenagem originária da bacia do rio Claro dirige-se para a bacia do rio Tietê, enquanto a do rio Guaratuba dirige-se para o Oceano Atlântico, mudando de direção na borda da Escarpa, passando de NE-SW para N-S. Apresenta rede hidrográfica com padrão em treliça, devido ao intenso fraturamento e natureza bandada da rocha, orientada, em sua maioria na direção NE-SW e, subordinamente a NW-SE, com inserção de rios em ângulos agudos a retos, devido ao alto controle geológico/estrutural. É uma zona com morros e desníveis altimétricos de até $300 \mathrm{~m}$. As declividades são variadas, abrangendo desde pequenas planícies ao longo dos principais cursos d'água, onde predominam declividades de $0^{\circ}$ a $2^{\circ}$ ( 0 a $3 \%$ ), até vertentes com declividades maiores de $25^{\circ}(46 \%)$.

O limite Planalto/Escarpa caracterizase por rupturas de declive convexas bruscas, sem cornija rochosa (ROSSI, 1999).

A Escarpa apresenta afloramentos rochosos e cicatrizes de escorregamentos, testemunhos de movimentos de massa. É caracterizada por relevo de denudação, com grande desnível altimétrico e paredões inclinados caindo abruptamente, com os maiores desníveis chegando a atingir $1.260 \mathrm{~m}$ no lado leste da bacia. Conforme ROSSI (1999), no trecho do Guaratuba, a escarpa corresponde ao subcompartimento de alta e média vertente, sobre granitos, onde dominam os declives entre 12 a $25^{\circ}$ (21 a $46 \%$ ), os mais acentuados na alta vertente. Apresenta rede de drenagem com padrão paralelo, com menor densidade de drenagem que no Planalto.

\section{Materiais}

Foram selecionadas as seguintes fotos-aéreas e cartas topográficas da área de estudo:

- Levantamento aerofotográfico do Estado de São Paulo, pancromático, na escala aproximada de 1:25.000, realizado pela Aerofoto Natividade em 1962, $n^{\text {os }} 7$ 9367, 79368 e 79369 e Levantamento aerofotográfico do Estado de São Paulo, pancromático, na escala aproximada de 1:25.000, realizado pela Base Aerofotogrametria e Projetos S/A em 1973, $\mathrm{n}^{\text {os }} 40.765,40.766,40.767,40.780,40.781$, 40.782;

- Carta topográfica Salesópolis, escala 1:50.000, folha SF23YDV1 e SF23YDV3, publicada pelo IGG-SP em 1971;

- Carta topográfica Salesópolis, escala 1:50.000, folha SF 23-Y-D-V-1/3, publicada pelo IBGE em 1984; 
- Cartas topográficas Serra Guaratuba e Fazenda Florestal do Rio Grande, escala $1: 10.000$, folhas SF23YDVISOD e SF23YDV1SOB, publicadas pelo IGC em 1988.

\section{Procedimentos}

O trabalho segue a abordagem da análise geomorfológica proposta por AB'SABER (1969) sobretudo nos seguintes níveis: 1) compartimentação da topografia, caracterizando e descrevendo as formas de relevo de cada compartimento, 2) obtenção de informações sistemáticas sobre a estrutura superficial da paisagem, através da observação da geologia e dos solos.

Trata-se de área de difícil acesso, com uma estrada que acompanha os rios Claro e Guaratuba até a represa de captação de água. Por essa razão, a maior parte das observações foi feita por fotografias aéreas. No entanto, há pontos de indefinição de drenagem, pela dificuldade de verificar a direção dos rios em foto-aérea e em campo, em função da grande densidade da vegetação e também pela imprecisão das

\section{cartas topográficas disponíveis.}

A fotointerpretação baseou-se no estudo dos seguintes fatores: tonalidade e textura, formas topográficas e drenagem conforme RICCl \& PETRI (1965), para elaboração da carta morfológica e da rede de drenagem.

Apresenta um embasamento cristalino cuja composição pouco varia. É constituído sobretudo por gnaisses de grã fina a média, porfiroblásticos ou não, de composição granítica, mais ou menos milonitizados, com ou sem segregados quartzo-silicáticos (veios, lentes e bolsões quartzosos ou pegmatóides) associados. Apresentando foliações miloníticas bem a muito bem desenvolvidas, concordantes com a direção geral NE-SW, mergulhos a SE, em parte com lineações minerais impressas em seus respectivos planos. Contudo, dentro deste quadro aparentemente homogêneo, há uma importante anisotropia textural devido ao próprio arranjo estrutural e granulométrico, e que condiciona boa parte da drenagem e dos interflúvios. 
FI GURA 3 - Niveis topograficos, morfologia e estrutura do Alto Guaratuba com interpretaçäo dos lineamentos estrutuuais.

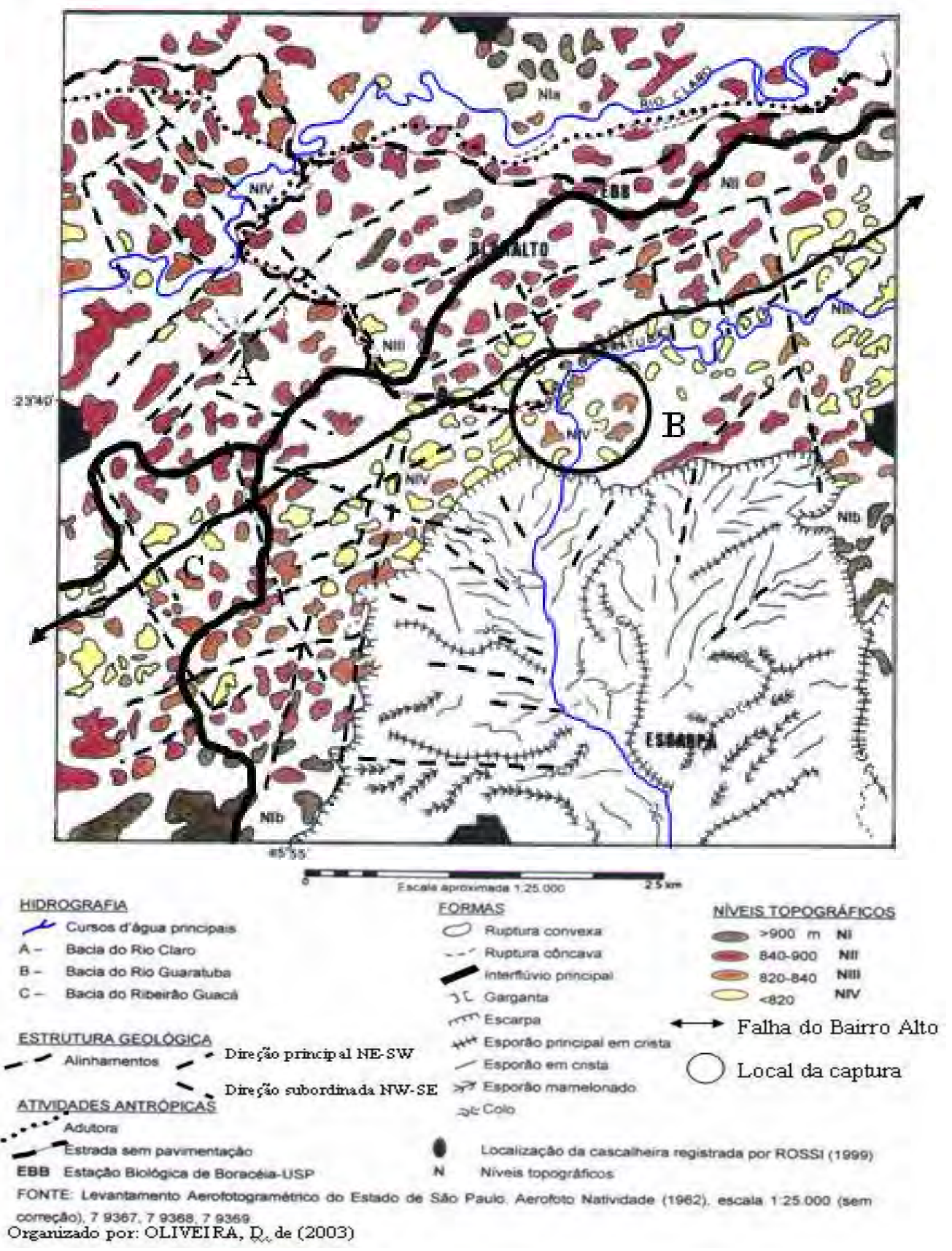


FIGURA 4 - Drenagem do Alto Guaratuba

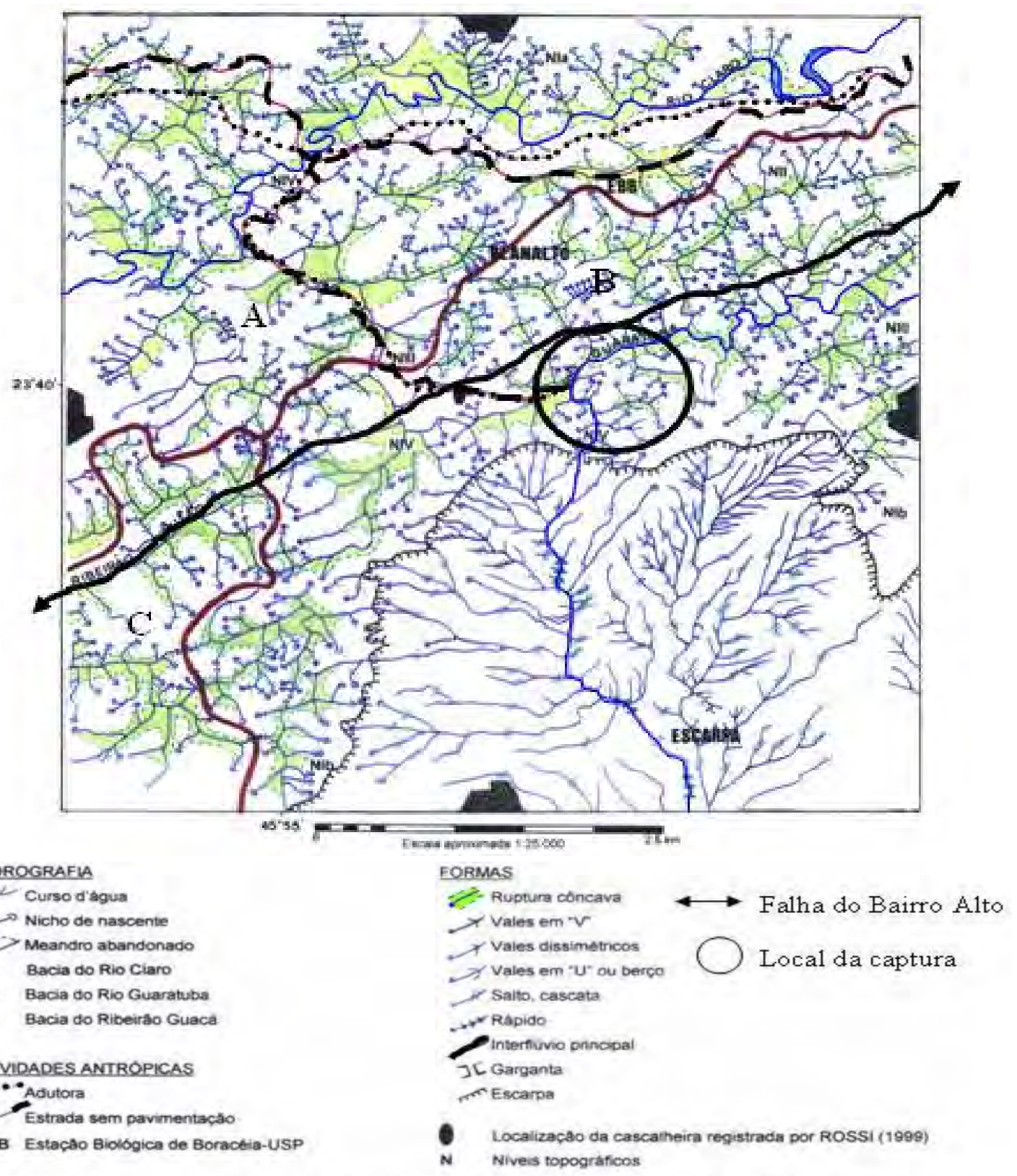

FONTE Levantamento Aerofotogrametrico do Estado de Sâo Paulo, Aerofoto Natividade (1962), escala 1:25.000 (sem correça), 7 9367, 7 9368, 79369

Organizado por: OLNEIRA, D de (2003) 
As formas foram assinaladas inicialmente delimitando os topos com rupturas convexas, que aparecem em grande quantidade em todo o Planalto, os limites das vertentes com as planícies com rupturas côncavas e posteriormente, delimitando a escarpa, os esporões em crista e mamelonados. A legenda da Escarpa foi adaptada de DOMINGUES (1983). Os níveis topográficos foram assinalados cruzando-se o overlay da morfologia com as curvas de nível das cartas topográficas Serra Guaratuba e Fazenda Florestal do Morro Grande no seguinte intervalo hipsométrico: $<820,820-840,840-860$ e $>900 \mathrm{~m}$. Por fim, procurou-se assinalar os alinhamentos, tanto da drenagem quanto dos morros (FIGURA 3).
Os procedimentos gerais de digitalização das curvas de nível, cotas, estradas e drenagem e elaboração das cartas e perfis, correspondem ao programa ILWIS, desenvolvido pelo Institute for Aerospace Survey and Earth Sciences (ITC), Enschede, Holanda, disponível em versão Windows. Trata-se de um sistema de informação geográfica, que conta com módulos de tratamento digital de imagens, de análise espacial e de entrada de dados. (WESTEN, 1997)

Com base nas cartas 1:10.000 foram digitalizadas todas as curvas de nível do Planalto e as curvas mestras da Escarpa e confeccionadas cartas na escala 1:25.000, compatibilizadas com a escala das fotosaéreas. 


\section{FIG URA 5 - Madelo hipsométrico sombreado do Alto} Guaratuba

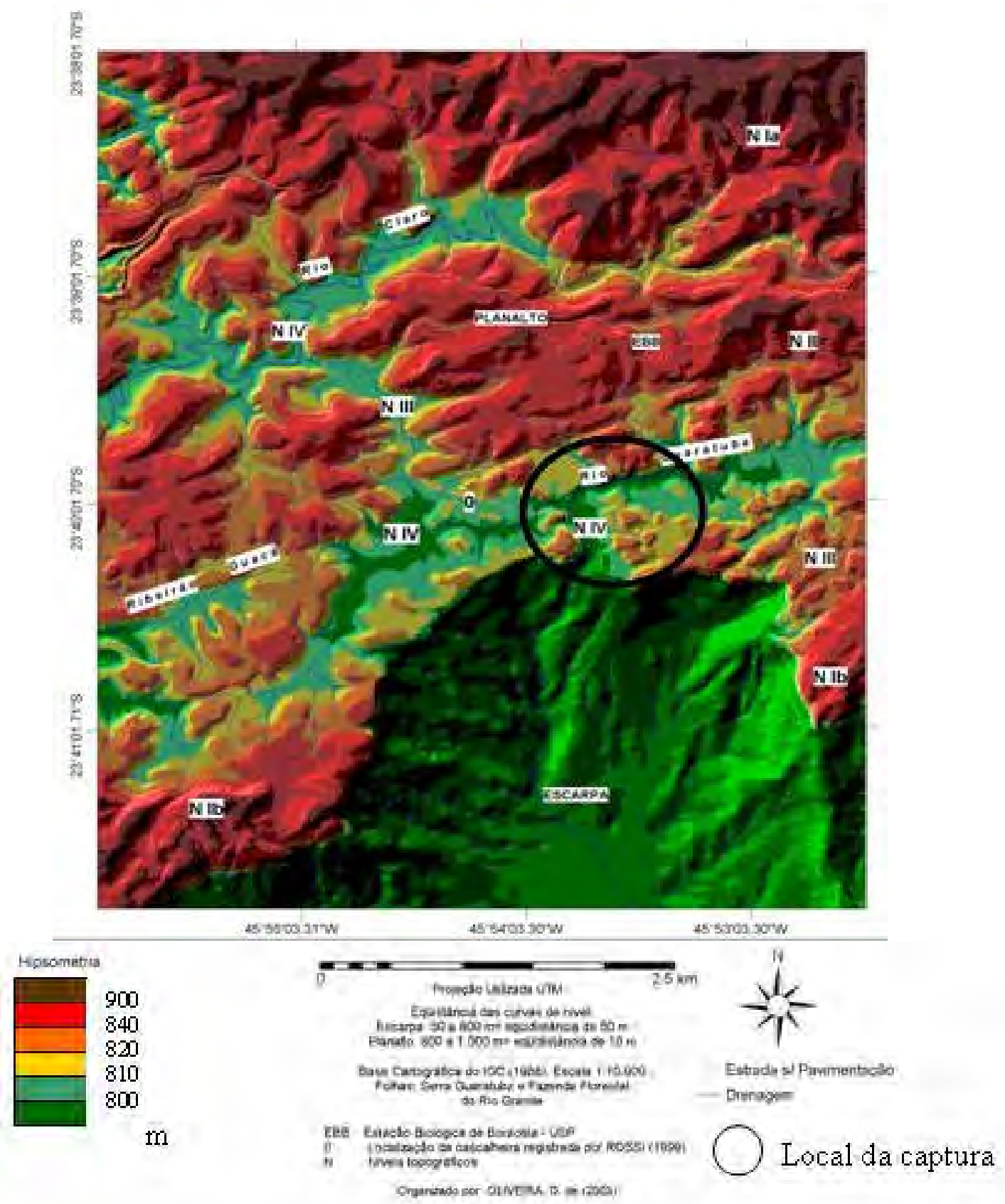


FIG URA 6 - Modelo tridimensional do Alto Guaratuba sobreposto ao modelo sombreado
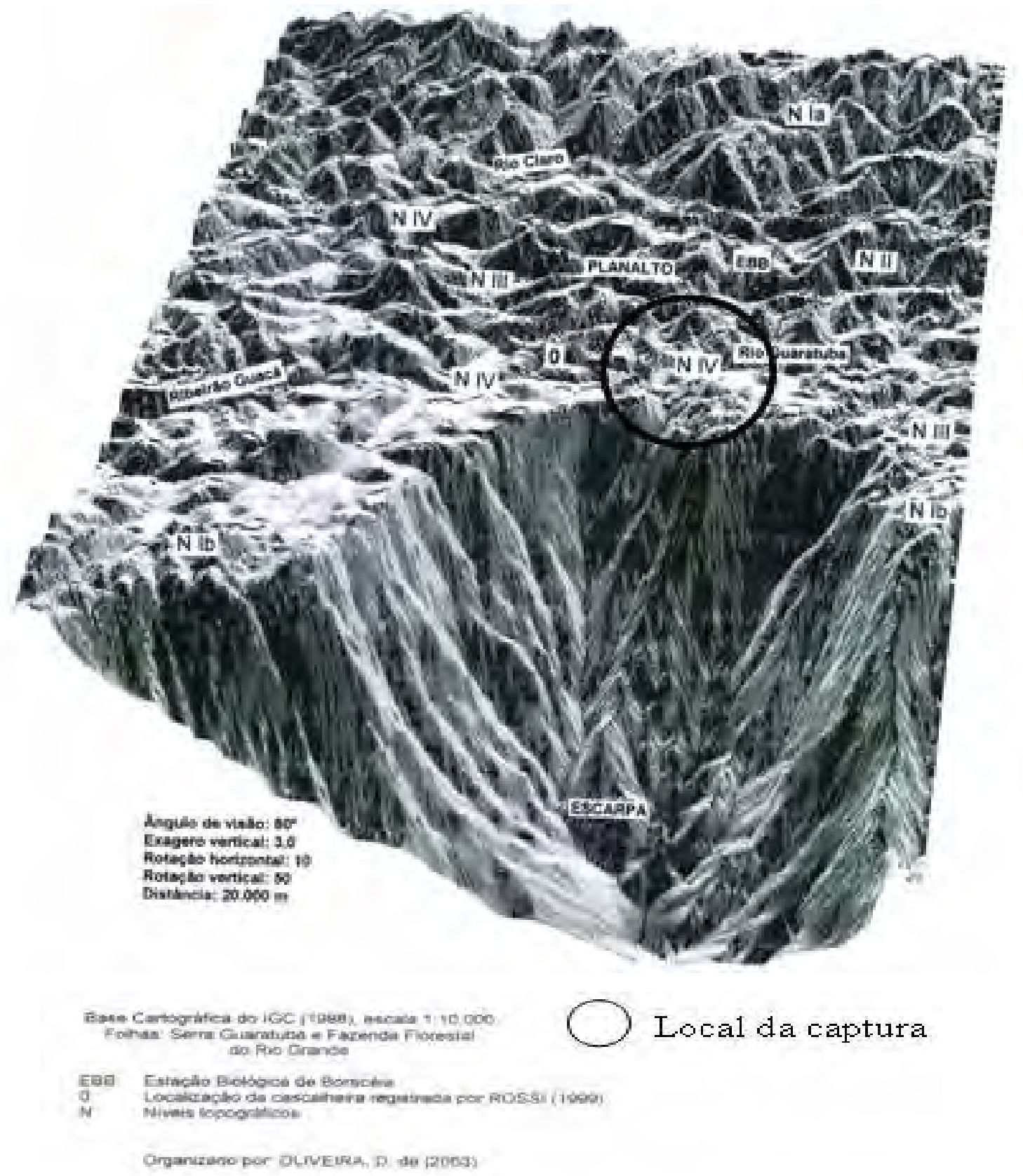

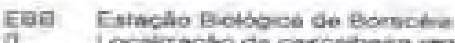

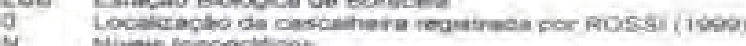

N Nivers icopeorticos

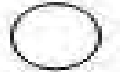

Local da captura 


\section{Resultados}

Os produtos cartográficos elaborados destacam nitidamente o Planalto da Escarpa, tanto quanto a densidade e padrões de drenagem, quanto a sua forma. A fotointerpretação preliminar mostrou que o Planalto apresenta grande densidade de pequenos morros alinhados na direção NESW, assim como os dois rios principais, o Claro e o Guaratuba (FIGURA 3). Foram identificados os seguintes níveis topográficos no Planalto: de $900 \mathrm{~m}$;

NIa e NIb - norte e sul da carta, acima $900 \mathrm{~m}$

$$
\text { NII - centro da carta, entre } 840 \text { e }
$$

NIII - corredor entre os rios Claro e Guaratuba, entre 820 e $840 \mathrm{~m}$ e

NIV - nas bacias dos rios Claro e Guaratuba, a menos de $820 \mathrm{~m}$.

O Planalto apresenta uma grande densidade de pequenos morros alinhados preferencialmente na direção NE-SW e subordinadamente na direção NW-SE, acompanhando a direção dos alinhamentos dos cursos d'água. O rio Guaratuba acompanha a direção da falha do Bairro Alto, posicionada na direção NE-SW. O divisor de águas que separa a bacia do rio Claro e Guaratuba também está também posicionado na direção NE-SW.

A Escarpa tem a forma de um grande anfiteatro côncavo. Sua borda apresenta muitos entalhes que se aproximam da drenagem no Planalto, iniciando a formação de gargantas. O rio Guaratuba, na Escarpa, apresenta um poder de entalhamento maior, devido a grande declividade, descendo bem encaixado em seu vale.

A drenagem do Planalto também está relacionada à presença de fraturas e falhas e é orientada, de modo geral, no sentido NESW. Predomina no Planalto a drenagem em treliça, que ocorre sob controle estrutural acentuado, composta por rios principais conseqüentes, recebendo afluentes subseqüentes que fluem em direção transversal aos principais, com fluência em ângulos retos (FIGURA 4). No Planalto como um todo predomina a angularidade média da rede de drenagem, relacionada a fatores estruturais e na Escarpa predomina a angularidade baixa, condicionada pelas altas declividades.

O anfiteatro da Escarpa apresenta esporões em crista e mamelonados que convergem para o rio Guaratuba, com padrão de drenagem pinado. A borda da Escarpa funciona como um divisor de águas entre o Planalto e a Escarpa. Muitos afluentes do rio Guaratuba deságuam neste rio ainda no Planalto, porém alguns rompem a borda da Escarpa, descendo o grande anfiteatro, aí desaguando no rio Guaratuba (FIGURA 3).

Os produtos cartográficos digitais ressaltaram os níveis topográficos representados na FIGURA 3. O Planalto está entre as curvas de nível de $790 \mathrm{~m}$ (no cotovelo do rio Guaratuba) e $970 \mathrm{~m}$. As altitudes mais elevadas encontram-se no norte e no sul da carta, configurando níveis topográficos posicionados na direção NE-SW, assim como os rios Claro e Guaratuba. O rio Guaratuba, em direção à sua nascente, apresenta um vale mais amplo, a $800 \mathrm{~m}$ de altitude, com direção geral NE-SW. Este vale torna-se mais encaixado em direção ao cotovelo, na borda da escarpa, onde muda de direção para $\mathrm{N}-\mathrm{S}$. O nível de base do rio Guaratuba é mais baixo do que o do rio Claro no Planalto. O cotovelo do rio Guaratuba está a $790 \mathrm{~m}$, enquanto o rio Claro está a $810 \mathrm{~m}$ de altitude. (FIGURA 5)

O modelo hipsométrico (FIGURA 5) e
o modelo tridimensional (FIGURA 6)
ressaltaram os níveis topográficos
identificados nas fotos-aéreas e propiciaram
a visualização dos níveis NIa e NIb com
aparência de "horst" e os níveis NII, NIII e


NIV como "gráben". O NIb aparece bem nítido interrompido, com o anfiteatro da Escarpa atingindo o cotovelo do rio Guaratuba.

o corredor entre os rios Claro e Guaratuba apresenta cascalheira em solos Espodossolo Hidromórfico e Gleissolo Pouco Húmico, registrada por ROSSI (1999). A fotointerpretação revelou a vegetação de campo úmido, confirmada em campo, onde encontra-se Gleissolo com seixos rolados, próximo à referida cascalheira. O campo úmido apresenta-se como uma clareira dentro da mata, com vegetação baixa e solo totalmente encharcado.
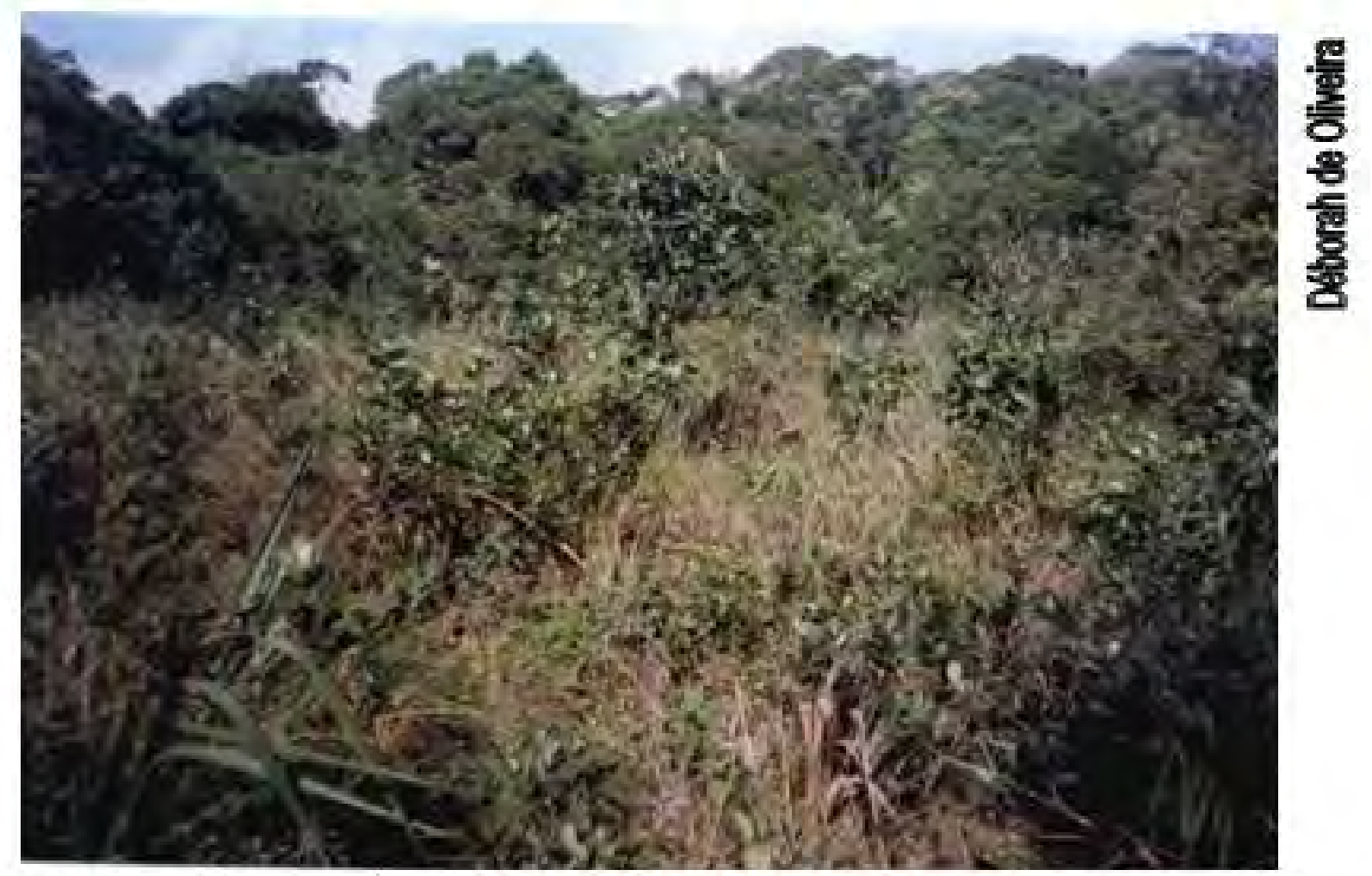

FOTO 1 - Campo úmido onde encontramos Gleissolo com seixos rolados, próximo à topossegüência estudada por ROSSI (1999)

No cotovelo do rio Guaratuba observamos o rio correndo oblíquo às estruturas do gnaisse e, em seguida, na borda da Escarpa, posicionado perpendicularmente aos alinhamentos NESW antes de descer a Escarpa em direção ao Oceano Atlântico. 

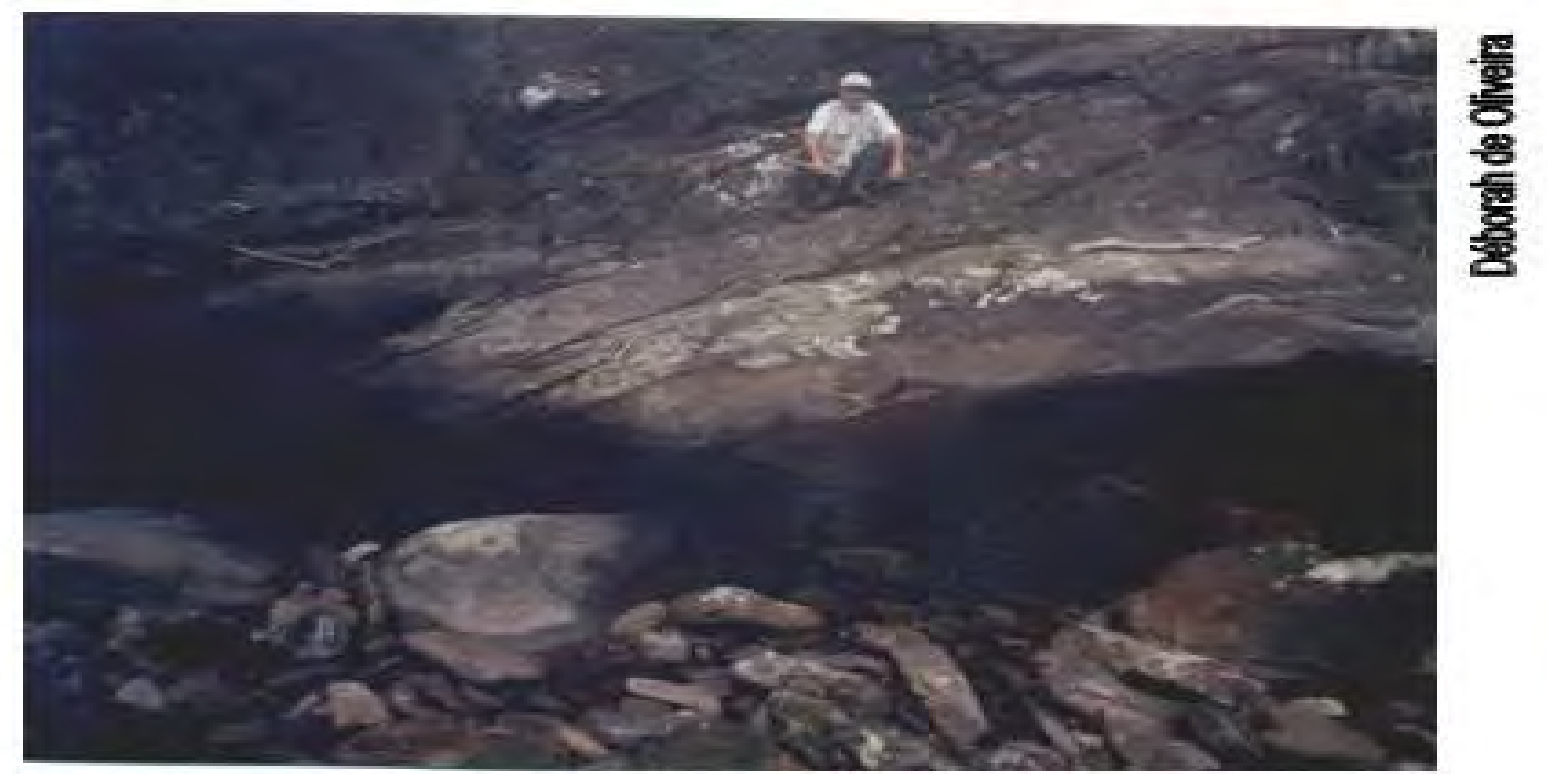

FOTO 2 - Rio Guaratuba correndo oblíquo às estruturas do gnaisse no final do cotovelo
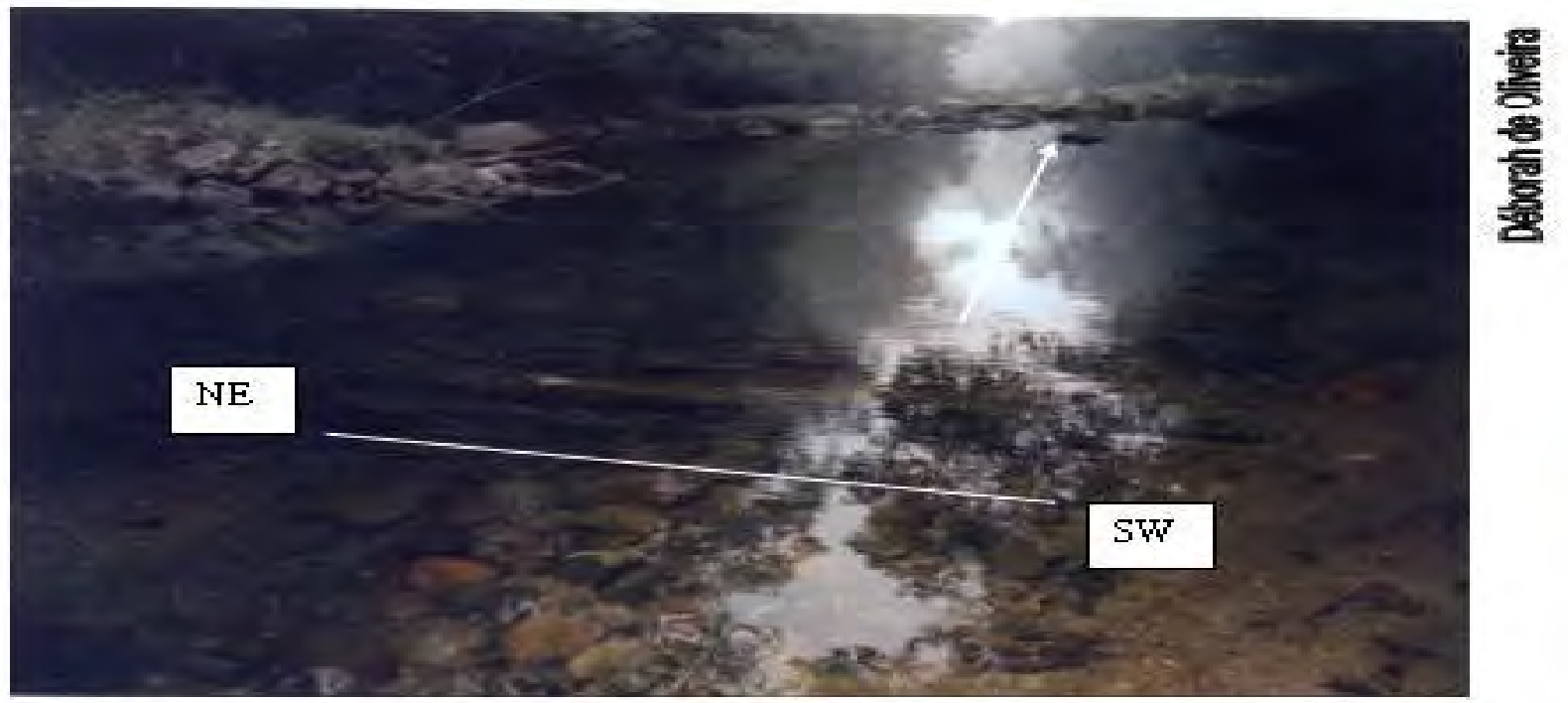

FOTO 3 - Rio Guaratuba correndo perpendicular às estruturas do gnaisse antes de descer a Escama

$\rightarrow$ sentido do rio Guaratuba

NE - SW direçẫo dos lineamentos estruturais 
O rio Guaratuba apresenta um perfil longitudinal com uma mudança brusca de declividade após seu cotovelo, quando desce a Escarpa, com desnível de 800m.

\section{PERFIL 1 - Perfil longitudinal do rio Guaratuba}

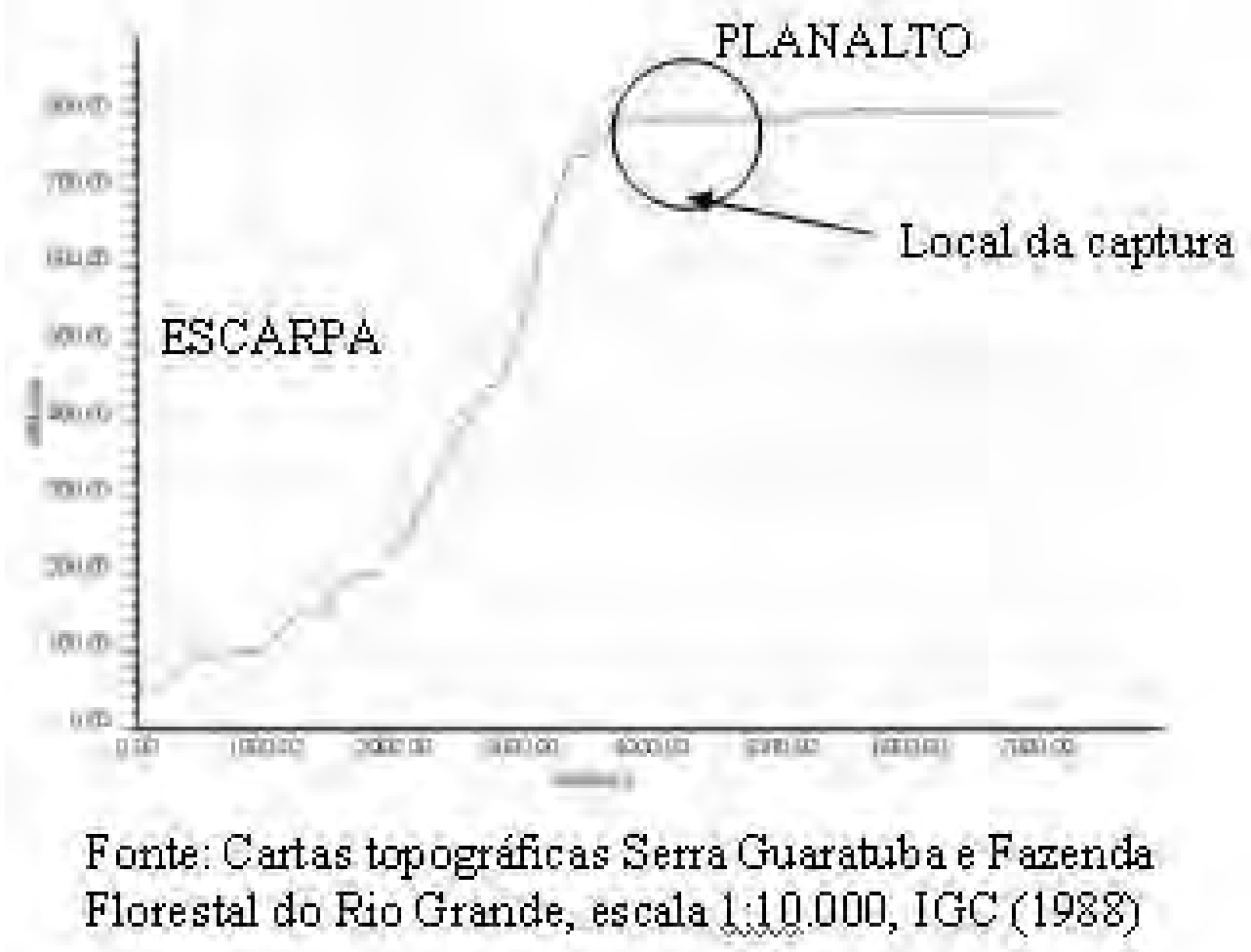

\section{Conclusões}

As informações fornecidas pelas cartas foram confirmadas no campo como evidências de captura fluvial apontadas por SMALL (1977): a presença do cotovelo de captura mostrando o rio Guaratuba deixando a direção brasileira NE-SW e passando a correr oblíquo às estruturas do gnaisse (FOTO 2), até posicionar-se perpendicular aos alinhamentos quando muda de direção para N-S na borda da Escarpa (FOTO 3); a presença de um vale abandonado, que no caso chamamos de campo úmido, pois apresenta-se como uma clareira dentro da mata, com vegetação baixa, solo totalmente encharcado e presença de seixos rolados (FOTO 1); o perfil longitudinal do rio Guaratuba (PERFIL $1)$, com ruptura de declive acentuado no cotovelo de captura e o nível de base do rio Guaratuba mais baixo do que o do rio Claro no cotovelo de captura. A reunião dos resultados obtidos mostra a interferência da tectônica na construção do relevo e da erosão na sua modelagem. A tectônica foi responsável pela elaboração dos níveis topográficos, com aparência de "horst e gráben", que hoje estão sendo destruídos pela erosão. 
O grande anfiteatro mostra que a erosão regressiva da Escarpa da Serra do Mar rompeu o nível NIb e capturou o rio Guaratuba, que antes corria em direção ao rio Claro, afluente do Tietê e, atualmente deságua no Oceano Atlântico.
As evidências deste caso de captura fluvial não foram destruídas no tempo e encontram-se presentes na paisagem, podendo indicar que as capturas fluviais na Serra do Mar podem ser mais comuns do que o registrado até agora.

\section{Notas}

${ }^{1}$ Parte da Tese de Doutorado do primeiro autor, financiada pela Capes.

\section{Bibliografia}

AB'SÁBER, A. N. Um conceito de geomorfologia a serviço das pesquisas sobre o Quaternário. Geomorfologia 18, São Paulo, Instituto de Geografia da USP, 23p., 1969.

AB'SÁBER, A. N. A geomorfologia do Estado de São Paulo. In: Aspectos Geográficos da Terra Bandeirante. Rio de Janeiro: Conselho Nacional de Geografia, IBGE, 1954, 295p.

ALMEIDA, F. F. M. \& CARNEIRO, C.D.R. Origem e evolução da Serra do Mar. Revista Brasileira de Geociências, São Paulo, 28(2): 135-150, 1998.

CHRISTOFOLETTI, A. Capturas fluviais. In: Enciclopédia Mirador Internacional. São Paulo: 1975. vol. 5, p. 2049-2051.

DOMINGUES, E. N. Estudo de processos geomorfológicos do escoamento fluvial e evolução de vertentes na Serra do Cubatão, Serra do Mar-SP. 1983. 153f. Dissertação (Mestrado) - Departamento de Geografia, Faculdade de Filosofia, Letras e Ciências Humanas, Universidade de São Paulo, São Paulo.

IPT. Mapa Geológico do Estado de São Paulo, Série Monografias $n^{\circ} 6,2$ Vol., São Paulo, IPT, $126 \mathrm{p} ., 1981$.

MACHADO, L. Estruturação hortoniana de bacias hidrográficas do planalto paulistano e das escarpas da Serra do Mar-SP. 1979. $215 \mathrm{f}$. Dissertação (Mestrado), Departamento de
Geografia, Faculdade de Filosofia, Letras e Ciências Humanas, Universidade de São Paulo, São Paulo.

MILLER, A. M. Wind gaps. Science, Washington, p. 571-573, 1915.

OLIVEIRA, D. de A captura do Alto Rio Guaratuba: uma proposta metodológica para o estudo da evolução do relevo na Serra do Mar, Boracéia-SP. 2003. 105f. Tese (Doutorado) Departamento de Geografia-FFLCH-USP, São Paulo.

$\mathrm{RICCl}, M$ \& PETRI, $S$ Princípios de aerofotogrametria e interpretação geológica. São Paulo: Cia. Ed. Nacional, 1965. 226p.

ROSS, J.L.S. Relevo brasileiro: uma proposta de classificação. Revista do DG-USP, n 4, p. 25-39, 1985.

ROSSI, M. Fatores formadores da paisagem litorânea: a Bacia do Guaratuba, São Paulo Brasil. 1999. 168f. Tese (Doutorado) Departamento de Geografia, Faculdade de Filosofia, Letras e Ciências Humanas, Universidade de São Paulo, São Paulo.

SILVA, J. C. C. da. Contribuições aos estudos da geodinâmica ambiental do segmento leste do Pórtico Guanabarino, Niterói, RJ. 1999. 155f., Dissertação (Mestrado) - Pontifícia Universidade 
Católica de Minas Gerais, Belo Horizonte.

SMALL, R.J. The study of lanforms. Cambridge: Cambridge University Press, Iv., 1977.

WESTEN, V. Ilwis 2.1 for Windows- The integrated land and water information system
(User's Guide). Holanda: ITC, 1997. 511 p. ZALÁN, P. V. \& OLIVEIRA, J. A. B. de Origem e evolução estrutural do Sistema de Riftes Cenozóicos do Sudeste do Brasil. B. Geoci. Petrobras, Rio de Janeiro, v. 13, n.2, p, 269-300, 2005.

Trabalho enviado em setembro de 2007

Trabalho aceito em outubro de 2007 